This item was submitted to Loughborough's Research Repository by the author.

Items in Figshare are protected by copyright, with all rights reserved, unless otherwise indicated.

\title{
Multi-band material loaded Low-SAR antenna for mobile handsets
}

PLEASE CITE THE PUBLISHED VERSION

PUBLISHER

(C) Institute of Electrical and Electronics Engineers (IEEE)

LICENCE

CC BY-NC-ND 4.0

\section{REPOSITORY RECORD}

Panagamuwa, C.J., Maria I. Kitra, Patrick McEvoy, J.C. Vardaxoglou, and J.R. James. 2019. "Multi-band Material Loaded Low-sar Antenna for Mobile Handsets". figshare. https://hdl.handle.net/2134/2957. 
This item was submitted to Loughborough's Institutional Repository by the author and is made available under the following Creative Commons Licence conditions.

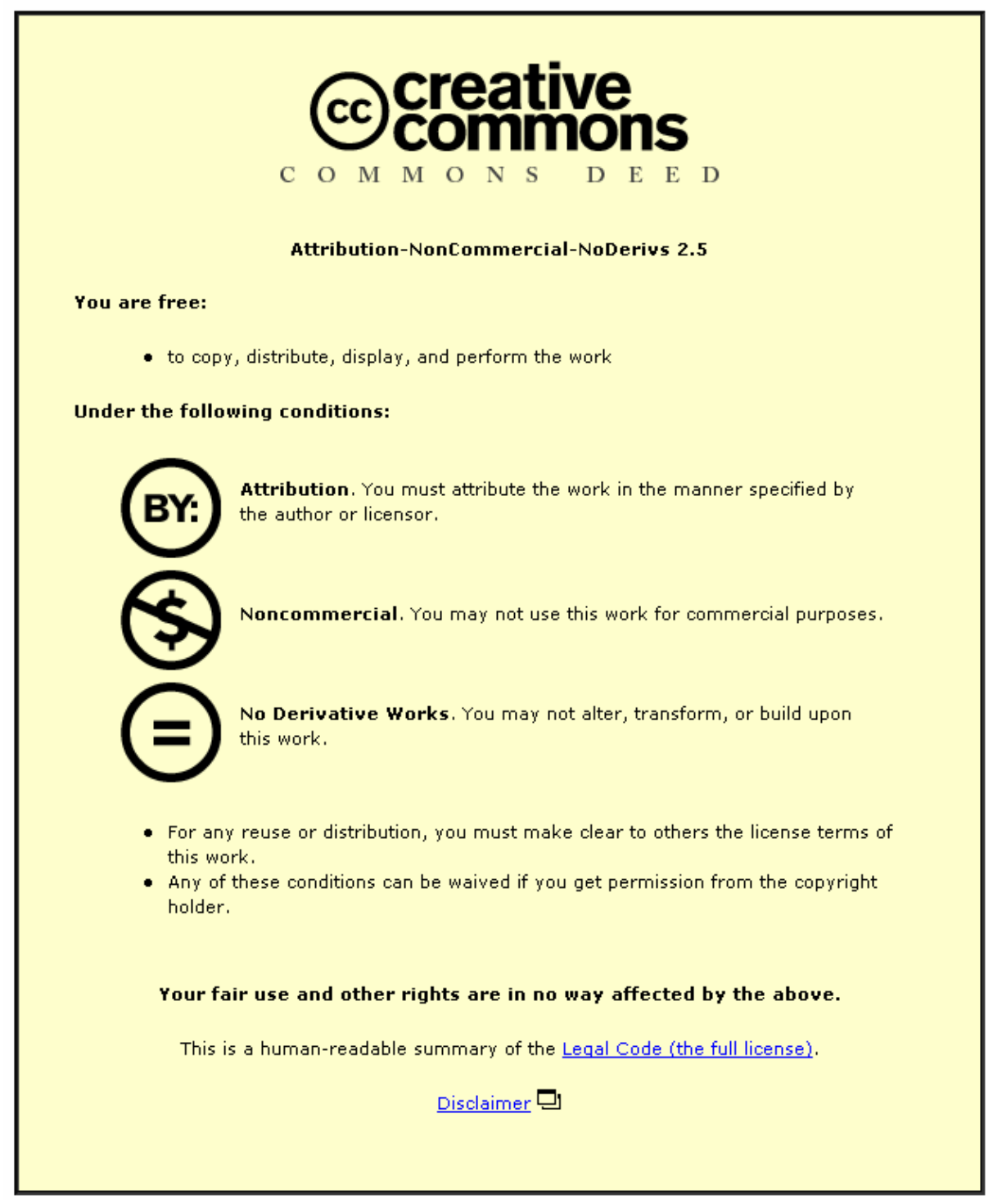

For the full text of this licence, please go to: http://creativecommons.org/licenses/by-nc-nd/2.5/ 


\title{
Multi-Band Material Loaded Low-SAR Antenna for Mobile Handsets
}

\author{
C.J. Panagamuwa, M.I. Kitra, P. McEvoy, J.C. Vardaxoglou, J.R. James \\ CMCR, Department of Electronic \& Electrical Engineering, Loughborough University, UK
}

\begin{abstract}
Previous studies have shown that monopoles loaded with material of equal permittivity and permeability values give increased bandwidth and radiation efficiency for a given size reduction. Positioning the monopole orthogonally to the head directs pattern nulls towards the head, which leads to low Specific Absorption Rates (SAR). Simulated results of the material loaded monopole showed dual-mode behaviour. In this paper, the simple monopole is translated into a compact antenna design suitable for mobile handsets. Metallic strips are printed on the material block to increase the number of modes and realise a small, quad-band, low-SAR handset antenna.
\end{abstract}

\section{Introduction}

Growing consumer demand for multifunctional mobile handsets has seen an increase in the development of small multi-band antennas. The ability to cover a number of communication bands with one small antenna benefits both the end user and the manufacturer as it reduces the cost and complexity of the antenna system and allows more versatile function of a compact handset. In addition, the handset can be made more attractive to the consumer by reducing the radiation absorbed in the head, i.e. the Specific Absorption Rate (SAR).

Antenna size reduction through the use of ceramic materials can lead to the bandwidth and efficiency being significantly reduced. It has been previously demonstrated that by including ferrite material, antenna size can be reduced while maintaining good efficiency and bandwidth [1]. High efficiencies are generally accompanied by high SAR values but careful orientation of the antenna can overcome this obstacle [2].

\section{Material composition and antenna orientation}

Initial studies on dielectric spherical resonators excited by small wire probes or loops based on analytical models, highlighted the benefits of introducing ferrite material into the resonators [1]. The benefits were shown to be applicable to a variety of shapes by extensive simulation of rectangular and other irregular shaped antennas using Flomerics' Micro-stripes ${ }^{\mathrm{TM}}$ based on TLM. Analysis showed maximum possible bandwidth and efficiency for any particular mode was achieved when the material's permittivity and permeability values were roughly equal $[1,2]$. For example, if the permittivity and permeability product of a ferrite loaded dielectric block excited by a dipole is kept constant at 36 , then maximum bandwidth and efficiency is achieved when $\varepsilon_{\mathrm{r}}=\mu_{\mathrm{r}} \cong 6$. Further studies showed the antenna's SAR was mainly dependent on its orientation with respect to the head and would dramatically reduce when the axis of symmetry of the antenna was orthogonal to the head [3]. With regards to a monopole, the ground plane is parallel to and the monopole is perpendicular to the head.

\section{Resonator antenna}

The dual-mode behaviour of a ferrite loaded dielectric resonator excited by a monopole has been previously investigated [4]. Two wrap-around open metal rings were used to introduce a third parasitic resonance, thus increasing the bandwidth and creating a tri-band antenna [5]. In this present paper, the antenna is incorporated onto a ground plane of a mobile handset. The change in ground symmetry distorts the radiation patterns necessary for reduced SAR, as pattern nulls into the head are disturbed. Here we describe the modifications made to the design to re-establish the pattern nulls into the head and increase the bandwidth.

The antenna is constructed on a $40 \mathrm{~mm} \times 100 \mathrm{~mm}$ ground plane and is shown in Figure 1 . The material block size is $32 \mathrm{~mm} \times 20 \mathrm{~mm} \times 10 \mathrm{~mm}$ and is positioned $5 \mathrm{~mm}$ from the top of the ground plane. It has the properties $\varepsilon_{r}=6$ and $\mu_{r}=6.6$. A $4.5 \mathrm{~mm}$ monopole excites the resonator block at the centre via a $50 \Omega$ coaxial feed. There is a $32 \mathrm{~mm} \times 9.9 \mathrm{~mm}$ metallic plate covering one vertical 
face and two printed rings, $1.5 \mathrm{~mm}$ apart that circle the block, one $0.5 \mathrm{~mm}$ wide and the other $2.9 \mathrm{~mm}$ wide. The antenna is designed and simulated in Flomerics' Micro-stripes ${ }^{\mathrm{TM}}$ TLM.

The large metallic plate over looking the ground plane is responsible for reforming the pattern null into the head. The rings act as parasitic resonators inducing further modes. Their frequencies can be controlled by altering the length, separation gap and position of the rings.

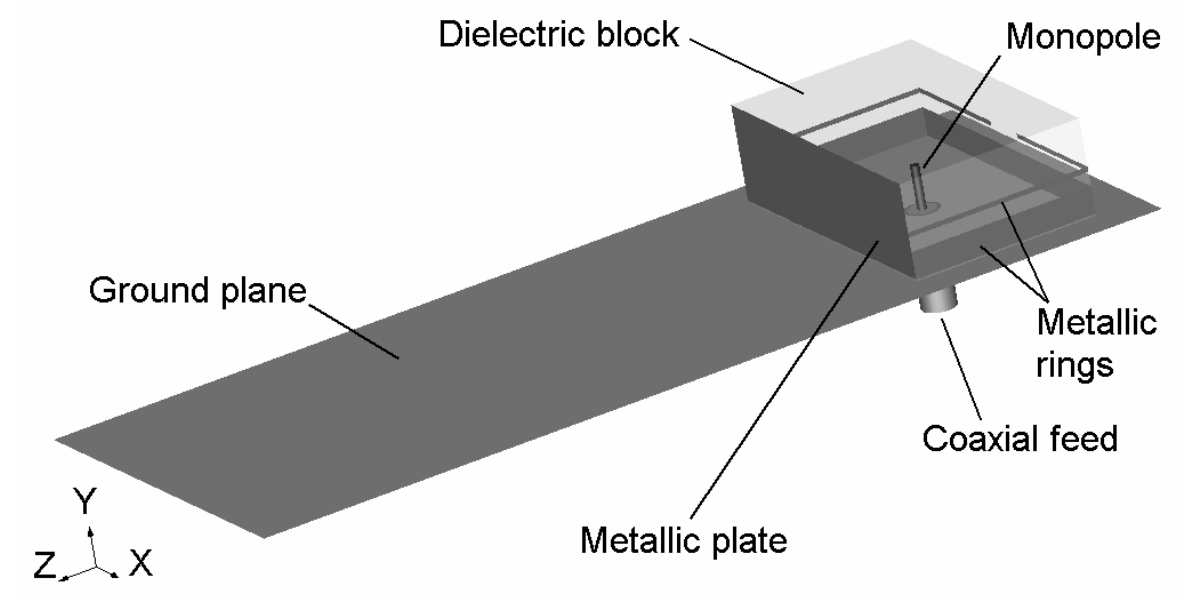

Figure 1 - Diagram of proposed quad-band handset antenna

\section{Results}

The simulated return loss for the antenna is shown in Figure 2. It shows coverage of GSM1800, GSM1900, UMTS and Bluetooth bands at $-6 \mathrm{~dB}$. The simulated radiation pattern cuts at $1.8 \mathrm{GHz}$, $1.9 \mathrm{GHz}$, and $2.1 \mathrm{GHz}$ in the yx and yz planes are given in Figure 3(a) and (b) respectively. There are clear pattern nulls into the head at $1.8 \mathrm{GHz}$ and $1.9 \mathrm{GHz}$.

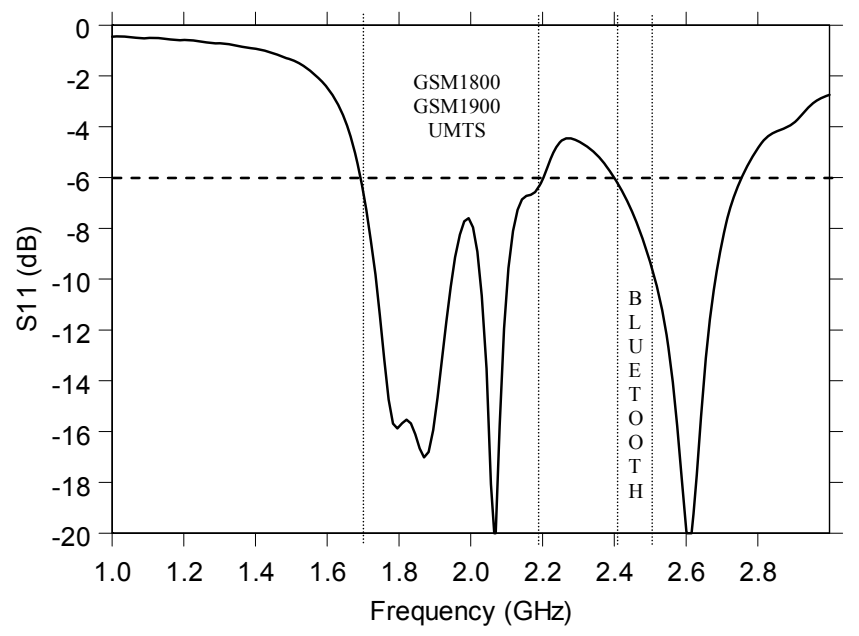

Figure 2 - Return loss for the quad-band antenna

The accuracy of the simulation package at predicting S-parameters and efficiency values has been successfully verified in the past by measuring ferrite loaded materials used in EM screening $[2,5]$. In order to check material variation influence on antenna performance and to align simulations to available materials with contemporary losses, two different loss combinations were simulated with $\varepsilon_{r}=6$ and $\mu_{r}=6.6$; (i) $\tan \delta_{\varepsilon}=\tan \delta_{\mu}=0.03$, (ii) $\tan \delta_{\varepsilon} \sim 0, \tan \delta_{\mu}=0.06$. For case (ii), the permittivity and permeability values were adjusted $(<6.4 \%)$ to $\varepsilon_{r}=6.38$ and $\mu_{r}=6.18$ to achieve comparative matching. 
The SAR values of the antenna were derived by simulating a homogeneous spherical phantom of radius $75 \mathrm{~mm}$. The material parameters of the phantom were $\varepsilon_{r}=41$, conductivity $(\sigma)=1.65 \mathrm{~S} / \mathrm{m}$ and density $(\rho)=1030 \mathrm{~kg} / \mathrm{m}^{3}$ in order to resemble human tissue. The handset was positioned such that the ground plane was parallel to and the monopole perpendicular to the surface of the sphere.

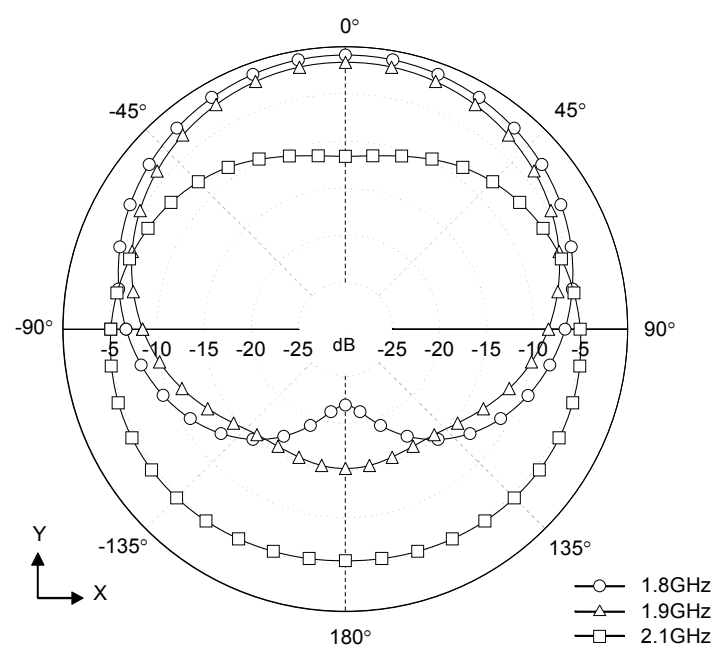

(a)

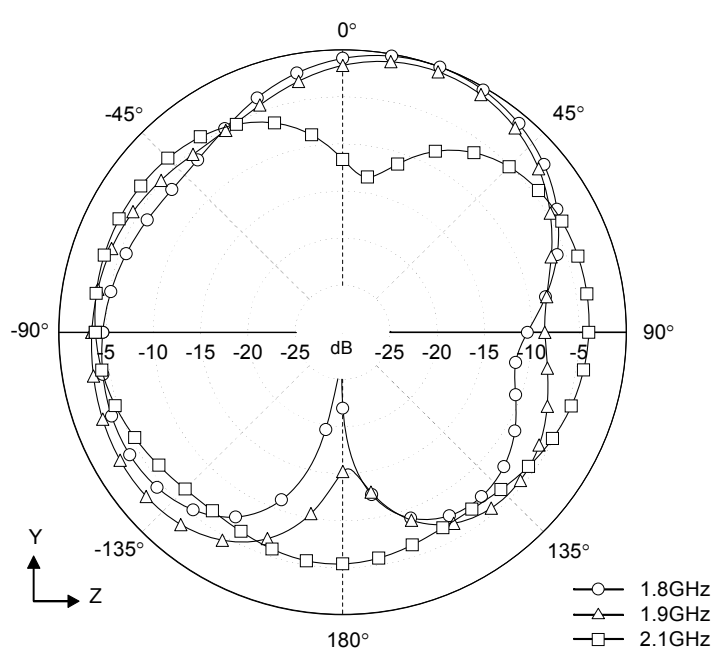

(b)

Figure 3 - Simulated radiation patterns in the (a) yx and (b) yz planes

The Table 1 summarises the results achieved from simulating the two dielectric resonator antennas. There is only a minor decrease in the antenna efficiency when placed next to a phantom head. This is in contrast to conventional PIFA and meander line antennas that have efficiencies of $60 \%$ that can reduce to $20 \%$ when positioned next to the head [6]. The radiation pattern cuts of the antenna when positioned next to the phantom head are given in Figure 4.

\begin{tabular}{|l|c|c|}
\hline & $\tan \delta_{\varepsilon}=\mathbf{0 . 0 3}, \tan \delta_{\mu}=\mathbf{0 . 0 3}$ & $\tan \delta_{\varepsilon}=\mathbf{0 . 0 0 0 1 ,} \tan \delta_{\mu}=\mathbf{0 . 0 6}$ \\
\hline $\mathbf{\varepsilon}^{\prime}$ & 6.00 & 6.38 \\
\hline $\boldsymbol{\mu}^{\prime}$ & 6.60 & 6.18 \\
\hline Monopole length (mm) & 4.50 & 4.50 \\
\hline $\begin{array}{l}\text { Coverage of GSM 1800, } \\
\mathbf{1 9 0 0 ,} \text { UMTS and Bluetooth } \\
\text { bands at -6dB }\end{array}$ & Achieved & Achieved \\
\hline $\begin{array}{l}\text { Efficiency (\%) at 1.8, 1.9, 2.1 } \\
\text { and 2.45GHz respectively }\end{array}$ & $36.8,36.1,19.1,27.5$ & $40.8,39.2,24,27.6$ \\
\hline $\begin{array}{l}\text { SAR 10g (W/kg) at 1.8GHz, } \\
\mathbf{1 . 9 G H z , ~ 2 . 1 G H z ~ a n d ~} \\
\mathbf{2 . 4 5 G H z}\end{array}$ & $0.076,0.11,0.06,0.0006$ & $0.077,0.106,0.07,0.0006$ \\
\hline $\begin{array}{l}\text { Efficiency (\%) with head at } \\
\mathbf{1 . 8 , 1 . 9 , 2 . 1} \text { and 2.45GHz } \\
\text { respectively }\end{array}$ & $35.05,32.6,15.15,22.34$ & $38.5,34.9,19.2,22$ \\
\hline $\begin{array}{l}\text { Efficiency (\%) with hand } \\
\text { and head at 1.8, 1.9, 2.1 and } \\
\mathbf{2 . 4 5 G H z ~ r e s p e c t i v e l y ~}\end{array}$ & $23.26,16.8,14.8,13.4$ & $25.4,11.7,13.4,13.2$ \\
\hline
\end{tabular}

Table 1 - Simulated design parameters and performance of quad-band rectangular ferrite loaded antenna 


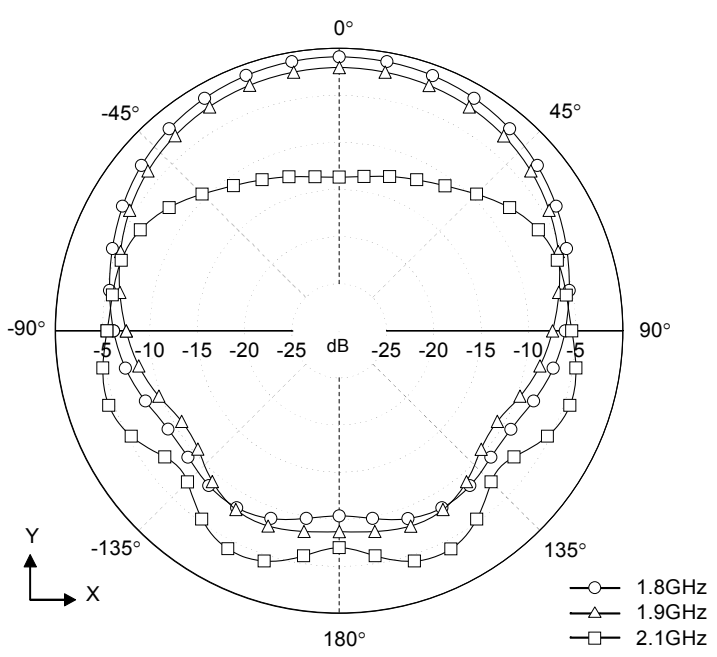

(a)

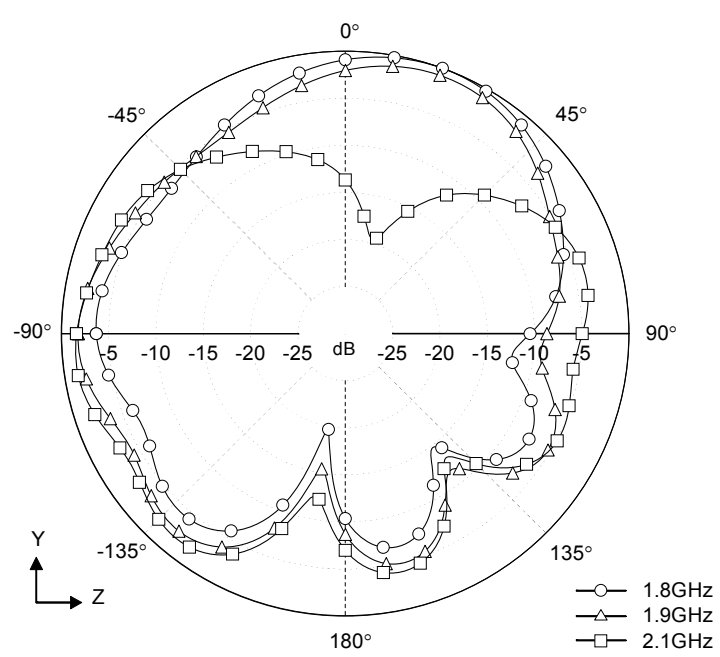

(b)

Figure 4 - Simulated radiation patterns with head in the (a) $\mathrm{yx}$ and (b) yz planes

\section{Conclusion}

Previous theoretical work concluding that equal permittivity and permeability in a dielectric resonator leads to maximum possible bandwidth and efficiency has been successfully translated to a practical multi-band handset antenna. The GSM1800, GSM1900, UMTS and Bluetooth bands have been covered at $-6 \mathrm{~dB}$ with good efficiency. The positioning of pattern nulls into the head has dramatically reduced the antenna's SAR. As a result, the antenna efficiencies show minimal change when positioned next to a head. This contrasts with PIFAs, which have high efficiencies in free space that drop significantly when positioned next to the head and inevitably lead to high SAR values. Measurement and simulation of available ferrite material has given promising results. Work continues on incorporating the GSM900 band.

The authors acknowledge the support of Flomerics in providing their Micro-stripes TLM tool. This work is funded by the UK EPSRC, Grant number GR/R94596101

\section{References}

1. M. I. Kitra, P. McEvoy, J. C. Vardaxoglou and J. R. James, "A theoretical and simulation study of dielectrically loaded antennas and their contribution towards low SAR", International ITG Conference on Antennas (INICA), pp. 245 - 248, September 2003.

2. M. I. Kitra, P. McEvoy, J. C. Vardaxoglou and J. R. James, "Material loaded antennas and their contribution towards low-SAR", IEE Antenna Measurements and SAR Conference, Loughborough University, May 2004.

3. M. I. Kitra, P. McEvoy, J. C. Vardaxoglou and J. R. James, "A theoretical and experimental study of dielectrically loaded antennas and their contribution towards low-SAR", IEEE AP-S International Symposium on Antennas and Propagation and USNC/URSI National Radio Science Meeting, pp. 3593 - 3596, June 2004.

4. M. I. Kitra, C. J. Panagamuwa, P. McEvoy, J. C. Vardaxoglou and J. R. James, "Investigation into the realisation of a low-SAR, dual mode material coated antenna for mobile handsets", IEEE International Workshop on Antenna Technology: Small Antennas and Novel Metamaterials, Singapore, March 2005.

5. M. I. Kitra, C. J. Panagamuwa, P. McEvoy, J. C. Vardaxoglou and J. R. James, "Feasibility of a triple mode, low-SAR material coated antenna for mobile handsets", Loughborough Antenna and Propagation Conference, pp. 229 - 232, April 2005.

6. Z. Li and Y. Rahmat-Samii, "Optimisation of PIFA-IFA combination in handset antenna design", IEEE Transactions on Antennas and Propagation, vol. 53, No. 5, pp. 1170 - 1778, 2005 . 